\title{
Improving Antithrombotic Management in Patients With Atrial Fibrillation: Current Status and Perspectives
}

\author{
Marcel Levi, M.D., Ph.D., ${ }^{1}$ F. D. Richard Hobbs, M.D., ${ }^{2}$ Alan K. Jacobson, M.D., ${ }^{3}$ \\ Ron Pisters, M.D., 4 Domenico Prisco, M.D., ${ }^{5}$ Artur Bernardo, M.D., 6 \\ Markus Haas, Ph.D., ${ }^{7}$ Jens Heidrich, Ph.D., 8 Matt Rosenberg, M.D., 9 \\ Jørn Dalsgaard Nielsen, M.D., ${ }^{10}$ and Walter A. Wuillemin, M.D., Ph.D. ${ }^{11}$
}

\begin{abstract}
Despite overwhelming evidence of the benefits of risk-adjusted oral anticoagulation on stroke reduction in patients with atrial fibrillation $(\mathrm{AF})$, there is still considerable undertreatment. A multidisciplinary expert group was formed to discuss issues surrounding anticoagulant treatment of patients with AF to try and achieve consensus on various aspects of the implementation of guidelines on oral anticoagulation therapy in AF. Panel members were cardiologists, hematologists, and laboratory and primary care physicians with specific expertise from Europe and the United States. One of the most important conclusions of the meeting was to enhance guideline adherence by better communication of the data showing that the benefits of stroke reduction outweigh the risk of bleeding associated with treatment with vitamin $\mathrm{K}$ antagonists. Management of oral anticoagulation therapy by dedicated centers, such as anticoagulation clinics, or by patient self-management may improve the quality of anticoagulation and facilitate the management of these patients and thereby further facilitate optimal antithrombotic management in patients with AF.
\end{abstract}

KEYWORDS: Atrial fibrillation, anticoagulation, warfarin, Coumadin, cerebrovascular thrombosis, thromboembolism, bleeding

Most patients with atrial fibrillation (AF) at a stage of their disease need to be treated with vitamin $\mathrm{K}$ antagonists (VKAs). Although current guidelines clearly define the indications for treatment, there are barriers among physicians and patients to the implementation of oral anticoagulation. The consensus meeting intended to
${ }^{1}$ Department of Vascular Medicine and Internal Medicine, Academic Medical Center, University of Amsterdam, Amsterdam, The Netherlands; ${ }^{2}$ Primary Care Clinical Sciences, University of Birmingham, UK; ${ }^{3}$ Loma Linda University School of Medicine, Department of Anticoagulation Services, Cardiology Section, Loma Linda VA Medical Center, Loma Linda, CA, USA; ${ }^{4}$ Department of Cardiology, University Hospital of Maastricht, The Netherlands; ${ }^{5}$ Department of Medical and Surgical Critical Care, Thrombosis Centre, University Hospital Careggi, Florence, Italy; ${ }^{6}$ Department of Cardiology, Klinik Gais, Gais, Switzerland; ${ }^{7}$ Theresienkrankenhaus, Academic Hospital, Mannheim, Germany; ${ }^{8}$ Laboratory Dr. von Froreich \& Kollegen GmbH, Hamburg, Germany; ${ }^{9}$ General Practitioner, Jackson, Michigan, USA; ${ }^{10}$ Thrombosis Centre, Gentofte Hospital,
Hellerup, Denmark; ${ }^{11}$ Division of Haematology, Luzerner Kantonsspital and University of Bern, Switzerland.

Address for correspondence and reprint requests: Marcel Levi, M.D., Department Internal Medicine, Academic Medical Centre F-4, Meibergdreef 9, 1105 AZ Amsterdam, The Netherlands (e-mail:m.m.levi@amc.uva.nl).

Antithrombotic Management of Atrial Fibrillation; Guest Editor, Marcel Levi, M.D., Ph.D.

Semin Thromb Hemost 2009;35:527-542. Copyright (C) 2009 by Thieme Medical Publishers, Inc., 333 Seventh Avenue, New York, NY 10001, USA. Tel: +1(212) 584-4662.

DOI 10.1055/s-0029-1240013. ISSN 0094-6176. 
delineate current international standards and to discuss strategies of how to implement and manage adequate VKA treatment.

The main reason for implementing anticoagulation is the higher risk of stroke and the associated higher mortality in AF patients who are not treated. Adjusteddose oral anticoagulation therapy reduces the risk for stroke efficiently, and this effect outweighs the risk for bleeding, particularly intracranial hemorrhage (ICH) ${ }^{1,2}$ AF prevalence is on the rise worldwide due to the increased elderly population. Therefore the number of elderly patients with AF who need VKA treatment will increase. When applying international guidelines such as the joint guidelines of the American College of Cardiology (ACC), the American Heart Association (AHA), and the European Society of Cardiology (ESC), 60 to $70 \%$ of AF patients should receive VKAs. ${ }^{1}$ However, most studies show underutilization of this effective treatment, irrespective of how patients are cared for.

\section{EPIDEMIOLOGY OF ATRIAL FIBRILLATION}

AF represents the most common arrhythmia in clinical practice. An estimated 2.5 million people in the United States and $>6$ million European Union citizens have paroxysmal or persistent $A F^{1,3-5}$ Incidence and prevalence of AF is age dependent. Due to the demographic change and an increasing proportion of the aged population with and without underlying heart disease, prevalence of $\mathrm{AF}$ is increasing worldwide with a growth rate of $\sim 2 \%$ per year. In the United States, the number of patients with $\mathrm{AF}$ has been projected to be $\sim 3.0$ million by 2020 , increasing to 5.6 million by $2050{ }^{3,4}$ Following an analysis from the Mayo Clinic in the Midwest, an increase of the number of adults with $\mathrm{AF}$ to 12.1 million has been projected and to as many as 15.9 million assuming a continued increase in the incidence of $\mathrm{AF}^{6}{ }^{6}$

The prevalence of AF correlates with age, affecting 0.4 to $1 \%$ of the entire population and increasing to $8 \%$ of the population $>80$ years of age. ${ }^{1}$ AF prevalence varies considerably between countries, although this may partly be a function of the methods of collecting the data and the demographics of the population investigated. In some countries, no specific epidemiological data have been reported. Prevalence of AF is $\sim 1 \%$ in Denmark, increasing with age up to $\sim 6 \%$ in those patients $\geq 80$ years of age. In Germany, the estimated number of patients with AF is 900,000 (diagnosed in 680,000). ${ }^{7,8}$ Based on the Echocardiographic Heart of England Screening study cohort, point prevalence in the UK general population is $1.7 \%$ in persons $>45$ years of age, with a maximum of $12 \%$ in subjects $>84$ years of age. ${ }^{9}$ In the United States, overall prevalence of diagnosed AF was estimated as $1.0 \%$ in the Anticoagulation and Risk Factors in Atrial Fibrillation study. ${ }^{3}$ It increases with older age, ranging from $0.1 \%$ among persons $<55$ years to $3.8 \%$ among persons $\geq 60$ years and $9.0 \%$ among persons $\geq 80$ years. In the Netherlands, overall prevalence of $\mathrm{AF}$ is $5.5 \%$, increasing from $0.7 \%$ at 55 to 59 years of age up to $17.8 \%$ at $\geq 85$ years of age. ${ }^{10}$ According to unpublished data from the Italian Longitudinal Study of Aging study, the prevalence ranges from $2.2 \%$ (65 to 69 years of age) to $5.4 \%$ (80 to 84 years of age). ${ }^{11}$ In a survey of 51 general practitioners in Northern Italy, a prevalence of $1.75 \%$ in 41,050 subjects $>40$ years of age has been found. ${ }^{12}$ According to an Italian survey on 9712 subjects 34 to 74 years of age, AF prevalence in men is $0.8 \%$ and $0.7 \%$ in women. ${ }^{13}$

Like prevalence, incidences of AF increase continually with age at the rate of $0.1 \%$ per year for those $<40$ years of age and $>1.5 \%$ per year for those $>80$ years of age. ${ }^{1}$ Overall incidence in Germany is reported $\sim 0.2 \%$, and overall incidence in the Netherlands is $1 \%$, increasing with age up to $2.1 \%$ in patients $\geq 85$ years of age. $^{10}$

\section{Consensus statement:}

- AF is a highly prevalent rhythm disturbance of the heart mainly affecting older people. Due to an aging population, the personal and economic burden of the disease is expected to increase in Europe and the United States.

\section{EFFICACY AND SAFETY OF ORAL ANTICOAGULATION THERAPY IN ATRIAL FIBRILLATION}

$\mathrm{AF}$ is a major contributor to stroke risk in the elderly. Ischemic stroke rate in patients with nonvalvular $\mathrm{AF}$ is up to 7 times that of people without AF, and the risk increases with age. ${ }^{14,15} \mathrm{AF}$ increases risk of stroke approximately fivefold, 15 to $20.3 \%$ of all acute stroke patients have $\mathrm{AF}$, and $36 \%$ of acute stroke patients $>80$ years of age have $A F{ }^{16}$ In many stroke patients, $\mathrm{AF}$ is first diagnosed at the time of the event. Although 18 to $21 \%$ of patients with $\mathrm{AF}$ are asymptomatic, ${ }^{17,18}$ they have an increased risk of stroke. Stroke is a leading cause of serious long-term disability in the United States with 15 to $30 \%$ being permanently disabled and $20 \%$ requiring institutional care at 3 months after onset.${ }^{19}$ Furthermore, $\mathrm{AF}$ increases mortality of stroke by $70 \%$, it doubles severity of stroke and increases stroke morbidity as evidenced by more stroke patients with AF in a bedridden state than stroke patients without AF, and it is associated with a higher recurrence rate and with an increase of silent cerebral infarcts. ${ }^{16,20,21}$ Taken together, untreated $\mathrm{AF}$ is associated with an increased mortality. ${ }^{21-23}$

Rates of stroke and hemorrhagic events are of primary interest in patients receiving oral anticoagulation therapy. Once the targeted intensity of oral 


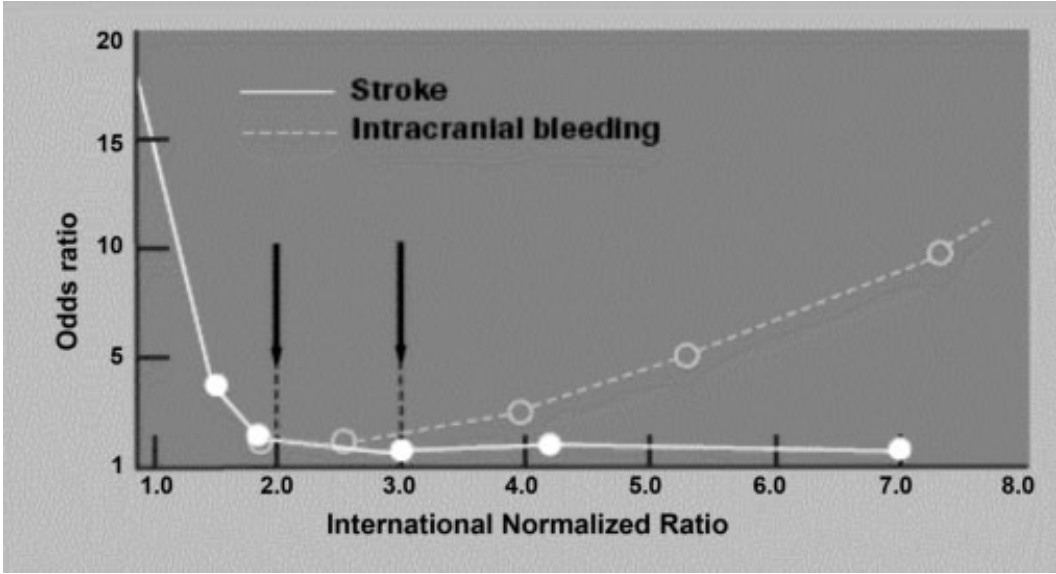

Figure 1 Significant increase in stroke risk with international normalized ratio (INR) values $<2.0$ and in intracranial bleeding risk with INR values over the range of 3.5 to $4.0 .^{2}$

anticoagulation is achieved, it must be maintained because this protocol is directly related to its derived benefit. ${ }^{1,24}$ The most recognized way to measure the therapeutic effectiveness of oral anticoagulation therapy is to measure international normalized ratio (INR) values. Time in therapeutic range, that is, the percentage of values in the targeted therapeutic range once a therapeutic INR has been established, correlates with the main clinical outcomes of bleeding or thrombosis but also represents a research tool for the evaluation of quality of overall care in these patients. ${ }^{24,25}$

Maintaining the intensity of anticoagulation is crucial to achieve effective stroke prevention as well as to avoid bleeding complications, particularly in elderly patients $^{2}$ (Fig. 1). For optimal outcomes it is essential to treat underlying heart disease such as coronary artery disease in addition to anticoagulation control in $\mathrm{AF}$ patients. ${ }^{1}$

\section{REDUCTION OF STROKE RISK}

The superiority of a risk-adjusted oral anticoagulation with VKAs compared with placebo or an aspirin-based therapy on stroke reduction has been clearly demonstrated by many prospective trials (Fig. 2). Oral anticoagulation reduces stroke events of any cause, not only embolic stroke, and it is also associated with a decrease of peripheral embolism. ${ }^{26}$ Most trials of anticoagulation in AF were terminated earlier due to overwhelming results in favor of anticoagulation. A meta-analysis of six major trials has demonstrated a risk reduction of stroke (both ischemic and hemorrhagic) by $62 \%$ and of all-cause mortality by $26 \% .{ }^{27}$ Benefits of oral anticoagulation therapy may even have been underestimated because between $25 \%$ and $93 \%$ of patients were excluded in landmark trials on oral anticoagulation therapy in AF patients (e.g., patients with previous stroke).

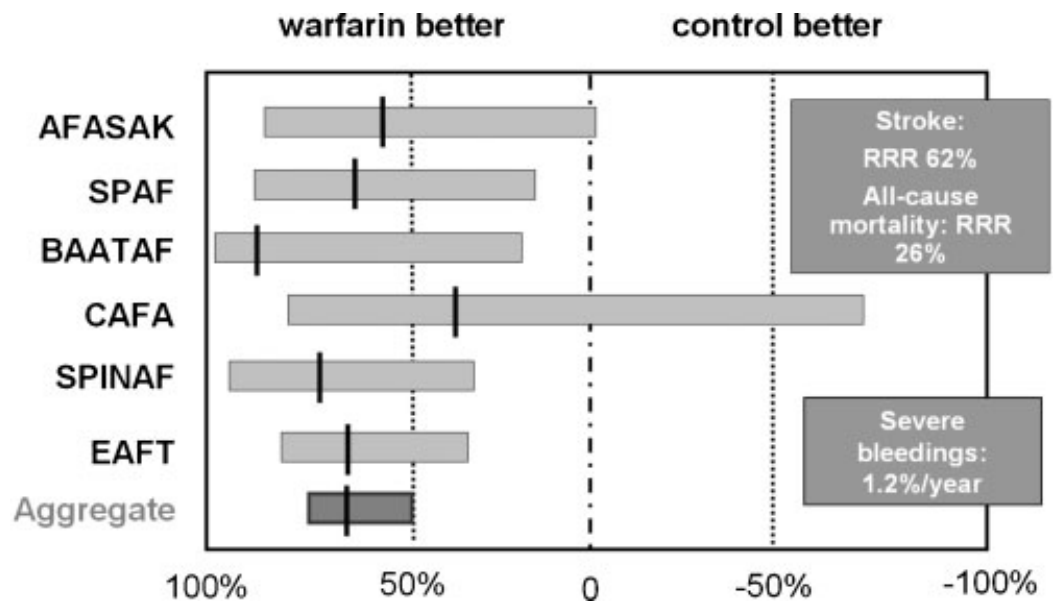

Figure 2 Reduction of stroke risk by oral anticoagulation therapy in prospective atrial fibrillation trials. Adapted from Hart et al. ${ }^{27}$ AFASAK, Atrial Fibrillation, Aspirin, and Anticoagulation study; BAATAF, The Boston Area Anticoagulation Trial for Atrial Fibrillation; CAFA, Canadian Atrial Fibrillation Anticoagulation study; EAFT, European Atrial Fibrillation Trial; RRR, relative risk reduction; SPAF, Stroke Prevention in Atrial Fibrillation study; SPINAF, Stroke Prevention in Nonrheumatic Atrial Fibrillation study. 
In a pooled analysis of five large randomized controlled trials, oral anticoagulation with warfarin decreased the risk of stroke by $68 \%$ in patients with $\mathrm{AF}$, from $4.5 \%$ in the control group (placebo) to $1.4 \%$ in the warfarin group. $^{28}$ Stroke reduction was more pronounced in women compared with men. In a more recent meta-analysis by Hart et $\mathrm{al}^{29}$ that included 29 randomized, controlled studies with a total of $\sim 28,000$ patients, oral anticoagulation with a coumarin derivative was shown to reduce the risk of a stroke by $64 \%$ compared with the control group in patients with nonvalvular $\mathrm{AF}^{29}$ Warfarin efficacy is consistent across $\mathrm{AF}$ trials with 32 patients needed to treat for 1 year to prevent one stroke in primary prevention and 12 patients in secondary prevention. Oral anticoagulation may be most beneficial for AF patients at higher intrinsic thromboembolic risk. ${ }^{1}$

In addition to superiority over placebo, there is clear evidence of the efficacy of adjusted-dose oral anticoagulants to reduce stroke, disabling stroke, and other major vascular events for those with nonvalvular $\mathrm{AF}$ when compared with antiplatelet therapy. ${ }^{2,27,30-41} \mathrm{Fi}^{-}$ nally, we now also have data on the superiority of warfarin in the elderly in a primary care setting. In the Birmingham Atrial Fibrillation in the Aged (BAFTA) trial, patients $\geq 75(n=973)$ were either treated with 75 $\mathrm{mg}$ /day aspirin or warfarin targeting an INR of 2.5 (range, 2.0 to 3.0). ${ }^{42}$ There was a significant benefit of warfarin over aspirin treatment in terms of stroke prevention ( $1.8 \%$ versus $3.8 \%$ annually). This benefit was maintained in all subgroups of AF patients. Adherence to warfarin was less than adherence to aspirin in the BAFTA trial. Warfarin's relative superiority over aspirin for prevention of ischemic stroke is maintained in paroxysmal $\mathrm{AF}$, prior stroke or transient ischemic attack (TIA), hypertension, heart failure, and diabetes.
It possibly is more effective in women and people $<75$ years of age. ${ }^{31}$

\section{SAFETY OF ORAL ANTICOAGULATION}

Overall bleeding risk is increased with warfarin when compared with placebo, and hemorrhage is the major complication of VKA treatment. The rates of major bleeding, however, defined as bleeding severe enough to require hospitalization, blood transfusion, or surgery, were not significantly worsened in AF trials when comparing adjusted-dose warfarin with placebo. ${ }^{27,28,43}$ $\mathrm{ICH}$, the most feared and devastating bleeding complication, ${ }^{44}$ is uncommon. In a meta-analysis of six trials conducted by Hart et al, ${ }^{27}$ the rate of ICH in adjusteddose warfarin was moderately higher among those taking warfarin $(0.3 \%$ per year) versus those not taking warfarin $(0.1 \%$ per year $)$ without reaching statistical difference (Fig. 3). The relative risk for major extracranial hemorrhage was 2.4 (95\% confidence interval [CI], 1.2 to 4.6), an absolute increase of $0.3 \%$ year for warfarin patients. ${ }^{27}$

However, there were concerns that the bleeding risk with warfarin was understated because many of the main trials excluded large numbers of patients from randomization, including those perceived to have higher bleed risk. ${ }^{45}$ Exclusion from studies would therefore result in a different risk-benefit ratio for these patients than in a real-world setting. ${ }^{45}$ Furthermore, observational data from the major warfarin versus aspirin trials suggested that the bleeding risks with warfarin were higher in the elderly, eliciting cautionary notes for warfarin use in those $>75$ years of age in clinical guidelines. ${ }^{31}$ Importantly, the BAFTA trial was designed to test these concerns by randomizing patients $>75$ years of age with minimal ineligibility criteria and demonstrated the bleeding risk with warfarin was the same as for

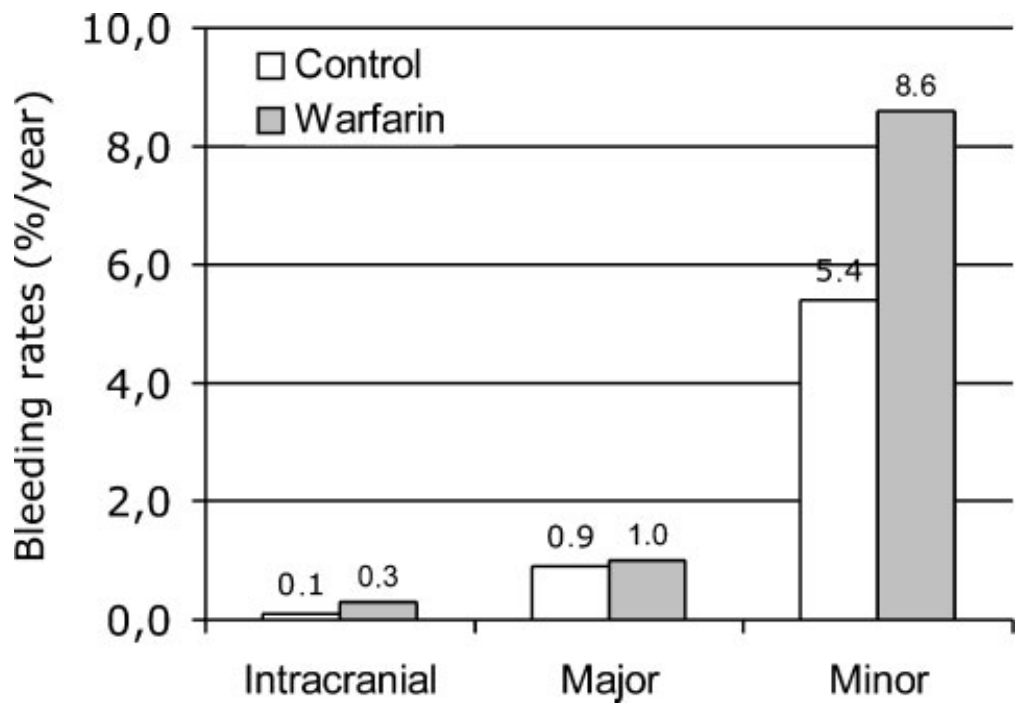

Figure 3 Bleeding rates in atrial fibrillation trials. ${ }^{28,43}$ 
aspirin. ${ }^{42}$ These analogous bleeding findings are confirmed in the meta-analysis update. ${ }^{46}$

The risk of major hemorrhage and $\mathrm{ICH}$ in $\mathrm{AF}$ patients is mainly related to inadequate oral anticoagulation therapy. Overtreatment with persistent INR values $\geq 4$ is associated with an increased risk of major hemorrhage, especially among older patients. ${ }^{2,47}$ Therefore, dedicated monitoring of INR values helps to prevent $\mathrm{ICH}$ among patients with $\mathrm{AF}$ receiving oral anticoagulation therapy.

\section{Consensus position:}

- Risk-adjusted oral anticoagulation therapy in AF significantly reduces stroke rates, whereas major bleeding rates are not increased compared with placebo or aspirin within the therapeutic range of INR 2.0 to 3.0 .

- In high-risk patients the benefit of stroke reduction outweighs the risk of bleeding associated with treatment with VKAs.

- Avoiding excessive INR values $\geq 4$ by way of dedicated monitoring helps to prevent ICH among AF patients.

\section{GUIDELINES ON THE IMPLEMENTATION OF ANTITHROMBOTIC THERAPY IN ATRIAL FIBRILLATION}

Practice guidelines such as the 2006 ACC/AHA/ESC Guidelines for the Management of Patients with Atrial Fibrillation ${ }^{1}$ or the Seventh American College of Chest Physicians (ACCP) 2004 guidelines $^{24}$ provide detailed recommendations relating to antithrombotic therapy in patients with AF. National guidelines such as those from the United Kingdom, ${ }^{48}$ Italy, $^{49}$ or Switzerland ${ }^{50}$ are mainly based on the ACC/AHA/ESC or ACCP guidelines.

Despite substantial differences among published schemes, ${ }^{51}$ scoring systems for stratifying stroke risk in patients with nonvalvular AF provide some guidance for implementation of oral anticoagulation therapy. The $2006 \mathrm{ACC} / \mathrm{AHA} / \mathrm{ESC}$ guidelines apply a risk-based approach using the clinical $\mathrm{CHADS}_{2}$ (cardiac failure, hypertension, age, diabetes, and stroke [doubled]) scoring system. ${ }^{52}$ In $\mathrm{CHADS}_{2}$, prior stroke or TIA is the strongest independent predictor of stroke followed by diabetes mellitus, history of hypertension, current or history of heart failure, and advanced age. ${ }^{1,28,53}$

Studies have identified INR $>4,{ }^{54}$ age $>80$ years, ${ }^{55}$ elevated blood pressure, ${ }^{56}$ prior ischemic stroke, ${ }^{54}$ and short-term tolerability of oral anticoagulants ${ }^{47}$ as major risk factors for intracranial bleeding (Table 1). Especially the latter two risk factors underline the need for adequate initiation of oral anticoagulation in high-risk AF patients. Anticoagulation of elderly patients with
Table 1 Clinical Risk Factors for Major Hemorrhage during Oral Anticoagulation Therapy*

Firmly linked

Advanced age $\geq 80 \mathrm{yr}$

Intensity of oral anticoagulation (INR $\geq 4$ )

Prior ischemic cerebrovascular disease

Hypertension (especially systolic)

Occasionally reported

Atrial fibrillation

Diabetes mellitus

Proximity to initiation of anticoagulation $(<90 \mathrm{~d})$

Concomitant use of antiplatelet agents

Prior hemorrhage

Dementia

Liver disease

History of falling

Renal dysfunction (creatinine concentration

$>130 \mu \mathrm{mol} / \mathrm{L}$ or $1.5 \mathrm{mg} / \mathrm{dL}$ )

Active malignancy

Potential precipitating events

Minor head trauma

Acute alcohol intoxication

Acutely elevated blood pressure

Severe migraine attack

*Adapted from 47,54-56,58,59

INR, international normalized ratio.

AF should be accompanied by tight control of hypertension because modest reductions in blood pressure considerably reduce the risk of $\mathrm{ICH} .{ }^{57}$

\section{CURRENT RECOMMENDATIONS}

According to the ACC/AHA/ESC guidelines, patients with prior stroke, TIA, other thromboembolism, or with rheumatic heart disease are at highest risk for stroke and clearly need oral anticoagulation. The guidelines specify when risk factors indicate that aspirin is sufficient for antithrombotic treatment and when risk factors suggest a patient is a candidate for oral anticoagulation therapy (Table 2). VKAs are indicated if a patient has one highrisk factor or more than one moderate risk factor. Aspirin is sufficient in a patient with no other risk factors for stroke. If there is one moderate stroke risk factor, either aspirin or VKAs can be used, according to patient and physician preference.

Oral anticoagulation is considered monotherapy for AF patients. The concomitant use of an antiplatelet agent and oral anticoagulation has proven not to be beneficial over oral anticoagulation monotherapy but rather seems to increase $\mathrm{ICH}$ risk in the elderly. ${ }^{61}$ Awaiting the results of the Atrial Fibrillation Clopidogrel Trial With Irbesartan for Prevention of Vascular Events-A trial, recent data from a post hoc subgroup analysis of the Clopidogrel for High Atherothrombotic Risk and Ischemic Stabilization, Management, and 
Table 2 Summary of Recommendations for Antithrombotic Therapy in Patients with Atrial Fibrillation Dependent on Risk Group and Definition of the Risk Groups

\begin{tabular}{lll}
\hline Risk Groups & Recommended Therapy \\
\hline No risk factors & Aspirin 81-325 mg/d & \\
One moderate risk factor & Aspirin 81-325 mg/d or & Oral anticoagulation (INR 2.0-3.0; target value: 2.5) \\
& Oral anticoagulation (INR 2.0-3.0; target value: 2.5) \\
A high-risk factor or $>$ 1 moderate risk factor & Moderate Risk Factors & High Risk Factors \\
Less Validated or Less Important Risk Factors & Age $\geq 75$ r & Previous stroke \\
Female gender & Hypertension & Mit or thromboembolism \\
Age 65-74 yr & Heart failure & Mechanical valve replacement* \\
Thyroid hyperfunction (thyreotoxicosis) & Left ventricular function $\leq 35 \%$ & \\
& Diabetes mellitus &
\end{tabular}

*For mechanical valve replacement, target INR $>2.5$.

INR, international normalized ratio; TIA, transient ischemia attack. Adapted from 60

Avoidance trial indicate the same holds true for dual antiplatelet therapy in low-risk patients. ${ }^{62}$ In anticoagulated patients with concomitant stents, antiplatelet therapy is managed according to stent guidelines and intensity of oral anticoagulation remains unchanged (INR, 2.0 to 3.0; target value, 2.5). In these patients, anticoagulation monitoring needs to be performed at an increased frequency.

Little data are available on the thromboembolic risk of the patient with atrial flutter. However, based on evidence that the thromboembolic risk is elevated compared with sinus rhythm patients but slightly lower than that of AF patients, ${ }^{63}$ the antithrombotic regimen is the same for both arrhythmias, atrial flutter and AF.

Except in AF patients with mechanical valves, the target INR should be 2.5 (range, 2.0 to 3.0). This is based on data demonstrating an INR $<2$ is not associated with a lower ICH risk in elderly AF patients compared with INR values between 2.0 and $3.0,{ }^{64}$ but both the risk for ${ }^{65}$ and mortality of ischemic stroke ${ }^{2}$ do increase when the INR drops below 2.0. In the EuroHeart Survey on AF, guideline-adherent antithrombotic treatment of high-risk patients was associated with improved outcomes compared with a higher chance of thromboembolism in undertreated patients. ${ }^{66}$ In this survey, overtreatment was not associated with a higher chance of major bleeding (Fig. 4).

Referral of AF patients to a specialist one time is strongly recommended when initiating antithrombotic therapy. For implementation and management of oral anticoagulation, therapy determination of INR is preferable over expressing the results as prothrombin time (PT) or Quick \%.

\section{Consensus position:}

- International practice guidelines such as the 2006 ACC/AHA/ESC guidelines provide helpful guidance on how to manage oral anticoagulation therapy in patients with AF.

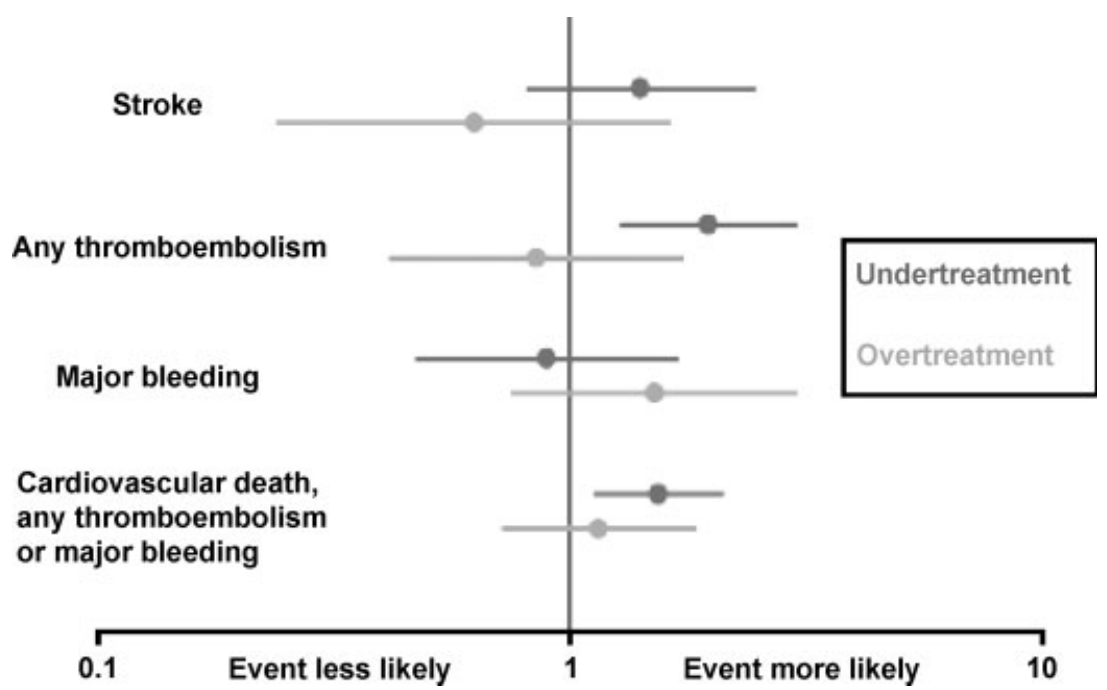

Figure 4 Multivariable effect of antithrombotic guideline deviance on 1-year outcome. Results are reported as odds ratio (OR) with $95 \%$ confidence interval compared with the reference group "guideline adherence" (OR, 1). ${ }^{66}$ 
- The antithrombotic treatment of patients with atrial flutter is the same as that for AF patients.

- Physicians should first evaluate stroke risk and bleeding risk in a given patient. Then risks and benefits of oral anticoagulation therapy should be discussed.

- If appropriate, oral anticoagulation should be initiated when one high-risk factor or more than one moderate risk factor are present.

- Oral anticoagulation therapy should be used as monotherapy in AF patients. The only exceptions are AF patients requiring concomitant clopidogrel treatment during the first 9 to 12 months after coronary stenting.

- Determination of INR is preferable over expressing the results as prothrombin time (PT) or Quick \%. The target INR value should be 2.5 (range, 2.0 to 3.0 ).

\section{IMPLEMENTATION OF ANTICOAGULATION GUIDELINES IN CLINICAL PRACTICE}

Although AF is highly prevalent in general practice and guidelines are in place, many patients are still undertreated or not treated at all. It has been estimated that worldwide an average of only $30 \%$ of patients with AF are treated with oral anticoagulation, ${ }^{67}$ whereas an estimated 60 to $70 \%$ should be. ${ }^{1}$

In Germany and the Netherlands, $\sim 60 \%$ of patients are treated according to guidelines; in Denmark, $\sim 75 \%{ }^{7,14,60}$ Guideline adherence in Italy is not clearly known but may be $10 \%$ in a series of AF patients admitted to hospital with a first-ever stroke ${ }^{68}$ to $<50 \%{ }^{69}$ In a single-center study from Italy among 255 patients with nonvalvular AF admitted to an internal medicine ward from 2001 to 2005, 85\% of them high-risk patients, $62 \%$ received VKAs, but a fourth of these patients were undercoagulated. Among the highrisk patients, only $47.2 \%$ were adequately anticoagulated, $17.9 \%$ were undercoagulated, $23.4 \%$ received aspirin, and $11.5 \%$, no antithrombotic treatment. ${ }^{69}$ But patients not only are undertreated: In the Netherlands, overtreatment has been reported in as many as $18 \%$ of anticoagulated $\mathrm{AF}$ patients, ${ }^{14,66}$ exposing them to an increased risk of bleeding.

Whereas many high-risk AF patients are not anticoagulated adequately, it has been clearly demonstrated that guideline-adherent treatment is associated with improved outcomes. ${ }^{66,70}$ Several barriers to implementation of oral anticoagulation therapy exist.

\section{AWARENESS AND ESTIMATE OF TRUE RISK}

Strong evidence indicates that physicians underestimate the risk of stroke in their patients with $\mathrm{AF}$ and overestimate the risk of severe bleeding, particularly in the elderly. ${ }^{70-73}$ Unfortunately, stroke prevention as a pos- itive result of oral anticoagulation cannot be perceived by physicians directly. In contrast, major bleeding as a side effect of anticoagulation therapy can be experienced by physicians. Positive reinforcement pointing out the effectiveness of oral anticoagulation therapy is absent. As a consequence, physicians tend to ascribe stroke events to the disease itself and bleeding to treatment, and they fear iatrogenic complications but not stroke as the more frequent complication of AF. Accordingly, it has been shown that a physician's experience with bleeding events associated with oral anticoagulation therapy reduced warfarin prescribing, whereas the experience of stroke in a patient while not on warfarin did not affect subsequent prescribing. ${ }^{74}$

In another study, $15.8 \%$ of 596 general practitioners reported having a patient with AF experience an $\mathrm{ICH}$ with anticoagulation, and $45.8 \%$ had a patient with known AF experience a stroke without anticoagulation. ${ }^{75}$ However, only $45.6 \%$ of the physicians selected an anticoagulant in the presence of a minor falls risk when presented with a patient at "very high risk" of stroke, and $17.1 \%$ would anticoagulate if the patient had a treated peptic ulcer. ${ }^{75}$ Family physicians with less decisional conflict and those who were more experienced were more likely to endorse anticoagulation.

Among very elderly AF patients, the decision to prescribe oral anticoagulants is strongly influenced by contraindications. Hemorrhage, falls, and patient refusal or history of nonadherence to treatment constituted nearly $80 \%$ of the physician-cited reasons for not prescribing warfarin in AF patients who had been considered for anticoagulation therapy in one study. ${ }^{59}$

For many patients with AF, physicians' fears of the risk of bleeding related to anticoagulant therapy are often exaggerated and unfounded. Physicians should be aware of the impact of AF and the devastating consequences of not treating it adequately. They should also be able to discern absolute from relative contraindications. Strategies to optimize the management of $\mathrm{AF}$ should address psychological barriers to using anticoagulation as well. The key issue in selecting patients with $\mathrm{AF}$ for oral anticoagulation therapy is accurately estimating their stroke risk, with risk of hemorrhage during anticoagulation a lesser issue, relevant to only a few patients.

\section{ACCESS TO GUIDELINES}

Better access to the evidence base should enable clinicians to advise their patients appropriately. Often guidelines are too large and complex and, as a result, even specialists may not have consensus on treatment decisions (e.g., in patients presenting with high INR levels). Moreover, international guidelines are available only in English and not in local languages. What is more, few guidelines on oral anticoagulation therapy 
aim at the needs of general practitioners, which may include topics such as bleeding risk stratification, bridging therapy, or dual treatment with anticoagulants and antiplatelets. Because AF only represents a small part of a general practitioner's job, these physicians need simple guidance and suggestions for clear-cut decisions. This is critical to counter the concerns over treatment risk and perceived complications of oral anticoagulation therapy for some physicians. In some countries, the average general physician may not be well trained in treating AF but should be confident, as a minimum, about screening patients for $\mathrm{AF}$ and identifying those patients who need treatment. Special referral guidelines would also be of particular interest for general practitioners. They should help the physician to decide on when to refer the patient to specialist evaluation and treatment and to identify the "red flags" of oral anticoagulation therapy monitoring. Factors to consider include prevalence and costs; definition and symptoms; impact on patients, such as the risk of death and disability in stroke; diagnosis and assessment; and treatment options.

International and national guidelines should be harmonized and also be published and diffused in local languages and adapted to local practice patterns. Short and simple guideline versions should be prepared for use in primary care medicine. In addition to the complete paper version, an updated backup guideline Web site could be implemented. Guideline versions in electronic formats such as for personal digital assistants and personal computers as well as easy-to-use calculator tools should assist in balancing the benefits and risks of oral anticoagulation therapy for the individual patient.

\section{EDUCATIONAL ISSUES}

Physician specialty is an important determinant for VKA use. In a Dutch study, cardiologists showed best guideline adherence, whereas general practitioners were less adherent to guidelines. ${ }^{76}$ Similarly, in the Stroke and Atrial Fibrillation Ensemble II study, factors independently associated with prescription of oral anticoagulation were mainly related to the characteristics of the practitioner. ${ }^{77}$ Being followed up by a cardiologist or a younger general practitioner were the strongest predictors of VKA treatment. Underutilization of oral anticoagulation therapy as well as differences between treatment by general practitioners and specialists may therefore not only result from inappropriate perceptions of stroke and bleeding risks and consequences. Other reasons may be insufficient education, resulting in a lack of knowledge about oral anticoagulation therapy, and avoidance of responsibility for the patient.

Living with anticoagulants has become more demanding for patients than just taking the medication prescribed by the doctor. Patients therefore need to take responsibility by getting involved. The reward is control of the therapy in contrast to letting the therapy control the patients' lives. ${ }^{78}$ According to studies such as the West Birmingham Atrial Fibrillation Project, ${ }^{79}$ however, many patients with AF possess limited knowledge of $\mathrm{AF}$, its consequences, and therapies. Most patients (61\%) believed AF was "not serious," and many patients were not aware that AF predisposed to stroke. Only 52\% were aware of the reason for anticoagulation treatment, whereas the rest of the patients started therapy just because their "doctor told them to." A minority felt that their physician provided adequate information regarding warfarin therapy. ${ }^{79}$ Poor patient adherence to treatment is potentially a major source for poor anticoagulation control even among patients being treated in dedicated management systems where the importance of adherence is continually emphasized. ${ }^{80}$ The key to success is to communicate with patients to meet their requirements and improve their quality of life. Care of anticoagulated patients means to diagnose, educate, and treat them. Adherence rates are also related to access to INR testing and the burden of monitoring. ${ }^{81,82}$ In this regard point-of-care testing may offer advantages to physicians because rapidly available results enable them to communicate their treatment decision immediately to the patient.

Educational intervention programs improve knowledge about and/or control of oral anticoagulation therapy for AF..$^{83-85}$ Such programs may include regular teaching sessions, information booklets, workbooks, or slide presentations and can be addressed to individuals or groups of patients. However, education of the anticoagulated patient is time consuming for physicians and stuffed with learning content for patients, and therefore often neglected. Thus educational programs should attempt to maximize office efficiency by delegating this task to physician extenders, nurses, pharmacists, or perhaps an office-based computer. ${ }^{84}$ When written information is applied, the patient's reading skills have to be considered because the patient's reading abilities may be lower than the readability of the written information. It is important to have information that is understandable and culturally relevant to prevent the outcome of internal bleeding. ${ }^{86}$ Despite the practical value of making the patient as knowledgeable as possible, the best strategy for educating patients about anticoagulation is yet to be determined. ${ }^{84}$

\section{Consensus position:}

- International and national guidelines should be harmonized and be published and diffused in local languages and adapted to local practice patterns. Short and simple guideline versions should be prepared for use in primary care medicine. 


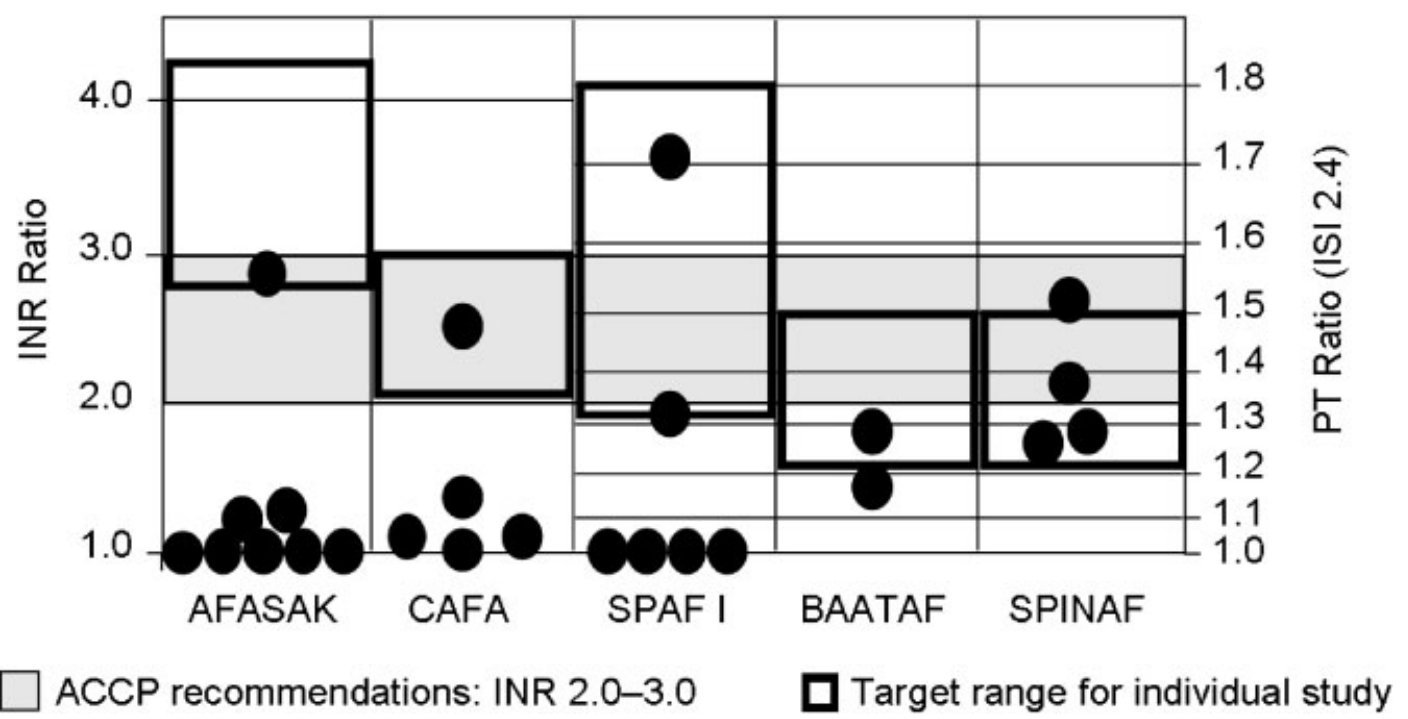

Figure 5 Intensity of anticoagulation when stroke occurred in patients assigned to warfarin in atrial fibrillation trials. ${ }^{32,88-92}$ Undercoagulated patients are more prone to have stroke (black balls). ACCP, American College of Chest Physicians; AFASAK, Atrial Fibrillation, Aspirin, and Anticoagulation Study; BAATAF, The Boston Area Anticoagulation Trial for Atrial Fibrillation; CAFA, Canadian Atrial Fibrillation Anticoagulation study; INR, international normalized ratio; ISI, international sensitivity index; PT, prothrombin time; SPAF, Stroke Prevention in Atrial Fibrillation study; SPINAF, Stroke Prevention in Nonrheumatic Atrial Fibrillation.

- In addition to the complete paper version of guidelines, an updated backup Web site may be prepared. It would be helpful to provide an easy-to-use calculator for balancing and checking benefits and risks of oral anticoagulation therapy in the individual patient in electronic formats.

- General physicians need better education on the management of oral anticoagulation and to be aware of the importance of $\mathrm{AF}$ and the consequences of not treating it adequately. Special referral guidelines may help them decide when to refer the patient to specialist evaluation and treatment and to identify the "red flags" of oral anticoagulation therapy monitoring.

\section{IMPACT OF UNDERUTILIZATION OF ANTICOAGULATION IN PATIENTS WITH ATRIAL FIBRILLATION}

When patients with AF do not receive any or no adequate oral anticoagulation therapy, the risk of stroke and death is increased. ${ }^{2}$ In a Swiss study, 16\% of stroke patients who had a history of AF were not on oral anticoagulation, providing evidence that for many of the stroke patients $\mathrm{AF}$ is diagnosed first at the time of stroke. In another study, $31 \%$ of unselected AF patients without contraindications were not treated with oral anticoagulants. ${ }^{70}$ If these patients had been treated according to guidelines, an estimated event rate of $4.9 \%$ per year could have been prevented. A metaanalysis of nine studies using a target conventional INR of 2.0 to 3.0 , the overall odds ratio for ischemic stroke for patients with INR $<2$ as compared with INR $\geq 2$ was 5.07 (95\% CI, 2.92 to 8.80 ) ${ }^{87}$ This means that undercoagulated patients with $\mathrm{AF}$ are significantly more likely to have stroke than those maintained within the recommended INR range (Fig. 5).

\section{ECONOMIC ASPECTS}

$\mathrm{AF}$ represents a considerable cost burden on health-care systems due to therapeutic interventions associated with increased AF morbidity and mortality. ${ }^{93}$ In the United States, the number of hospitalizations related to AF almost increased threefold in 2000 compared with 20 years ago. ${ }^{94}$ Fig. 6 shows the annual estimated costs of care and health resource utilization for the management of AF according to data from the United Kingdom, ${ }^{95}$ France, ${ }^{96}$ and the United States. ${ }^{97}$ In the UKbased survey, an increase of the National Health Service budget, from 0.6 to $1.2 \%$ in 1995 to 0.9 to $2.4 \%$ by 2000 , has been observed. ${ }^{95}$

Costs attributable to AF have to be considered in the context of different management strategies. In a pharmacoeconomic review, Szucs and Bramkamp showed that treatment with warfarin is highly cost effective both compared with aspirin or no therapy in patients with $\mathrm{AF}$ at moderate-to-high risk of stroke. ${ }^{98}$ The cost effectiveness of anticoagulation therapy is driven by the achieved risk reduction rather than the potential benefits estimated from clinical trials. Failure to maintain optimal anticoagulation places patients at risk of complications such as stroke, the management of which is a significant cost driver. ${ }^{98}$ Undertreatment with INR values outside the target range increases 


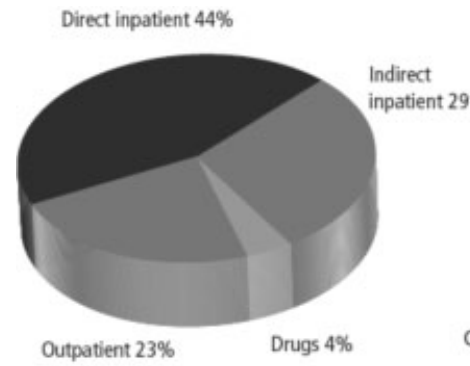

US: US56,650 million

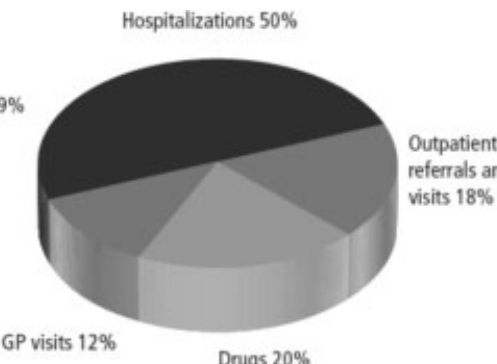

UK: US\$803 million

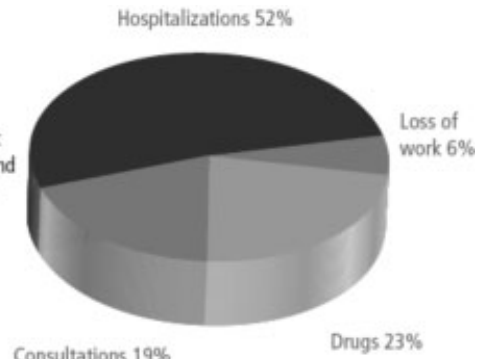

France: US\$2,605 million

Figure 6 Estimated annual costs of atrial fibrillation in the United States, ${ }^{97}$ United Kingdom, ${ }^{95}$ and France. ${ }^{96}$ GP, general practitioner.

hospitalization rates. ${ }^{19,99}$ A Canadian and a U.S. study showed that INR monitoring led to fewer complications as well as to lower costs for health-care professionals. ${ }^{100,101}$ However, only a small amount of the potential anticoagulation cost-saving benefit is currently attained due to undertreatment with VKAs. The U.S. study presented that if half of the AF patients in routine medical care currently receiving oral anticoagulation were optimally anticoagulated, $\$ 1.3$ billion would have been saved in 2004. Oral anticoagulation for stroke prevention, in addition to an optimized anticoagulation care, could even have saved up to $\$ 2.4$ billion.

\section{ANTICOAGULATION MANAGEMENT}

Anticoagulation management should consider various aspects of anticoagulation therapy that are addressed differently by different methods of anticoagulation management (Table 3). Not all management strategies work the same for all patients, and the physician should evaluate what works best for the individual patient for major convenience. A major problem for oral anticoagulation control independent from the strategy used is the instability of lifestyle of a patient as well as the loss of patients or lack of adherence ${ }^{80}$ during treatment. Anticoagulation management may also be complicated (e.g., by interacting drugs, diet, or traveling). Another major influence on INR variation results from the time point of testing, particularly when treating a patient with a substance having a short half-life such as acenocoumarol. ${ }^{102}$

\section{ELEMENTS OF ANTICOAGULATION MANAGEMENT}

Basically there are two styles of anticoagulation management: In the informal style, oral anticoagulation is managed by the individual practitioner who cares for the patient. In this essentially unstructured "usual care" option, patients may show up once per month. In contrast, a formal approach to anticoagulation management promotes systematic, structured care of the patients. The persons involved in structured care adopt an active attitude. The formal approach meets the requirements of "high quality anticoagulation monitoring" and is the preferred management style where available. ${ }^{103}$

INR testing can be performed in different ways. Blood may be sampled by venipuncture or by simple fingerstick, and INR values can be measured in a central laboratory or by point-of-care coagulometers. INR testing may be performed either by health-care professionals or by the patient or a surrogate at home (e.g., a nurse visiting older patients who are not able to manage self-testing on their own). All methods of INR testing are accurate and capable of providing reliable results. Anticoagulant dose may be adjusted by health-care professionals, as in the usual care or patient self-testing (PST) options, or by the patient or a surrogate, as in patient self-management (PSM). In any of these options, competency is needed to ensure correct dose adjustments.

Because factors such as medications, diet, and concurrent diseases can alter the pharmacokinetics of

\section{Table 3 Elements of Anticoagulation Management}

\begin{tabular}{ll}
\hline Elements & Options \\
\hline Management style & $\begin{array}{c}\text { Formal, structured anticoagulation } \\
\text { management } \\
\text { Informal, unstructured anticoagulation } \\
\text { management } \\
\text { Venipuncture, laboratory }\end{array}$ \\
$\begin{array}{l}\text { Method of INR } \\
\text { testing }\end{array}$ & $\begin{array}{l}\text { Point-of-care testing by patient or } \\
\text { surrogate }\end{array}$ \\
$\begin{array}{c}\text { Health-care professional } \\
\text { adjustments and } \\
\text { decision making }\end{array}$ & $\begin{array}{l}\text { Patient or surrogate } \\
\text { Frequency of testing }\end{array}$ \\
Historically once a month (4-6 wk) \\
More frequent in selected situations \\
Individually determined for each patient
\end{tabular}

INR, international normalized ratio. 
VKAs, frequent INR monitoring is necessary to ensure that a patient remains within therapeutic range. ${ }^{104}$ Health-care providers should assess their performance by monitoring INR regularly using a consistent methodology. Historically, oral anticoagulation therapy has been monitored once a month. Testing not only allows for dose adjustments but is also important for reassurance of the patients in terms of avoidance of bleeding. INR testing should be performed at least every 4 to 6 weeks, and more frequent testing of no longer than 2 weeks is required in selected situations such as unstable patients. ${ }^{24}$ Special considerations that may warrant more frequent testing are a huge bleeding risk or periods of instability. The International Self-Monitoring Association for Oral Anticoagulation 2005 guidelines recommend a testing interval of no longer than 4 weeks for stable patients and weekly testing for PST and PSM. ${ }^{105}$ Computerized decision support algorithms, which calculate monitoring intervals based on prior results, provide the optimum method for achieving good anticoagulation control, ${ }^{106-109}$ but they are not available everywhere.

\section{ANTICOAGULATION MANAGEMENT MODALITIES}

Traditionally four strategies of oral anticoagulation therapy management have been established: "usual" care by general practitioners or specialists, anticoagulation clinics, PST, and PSM. In the usual care option, patients are cared for, along with all other patients, by their personal physician. Table 4 presents an overview of the advantages and disadvantages of different anticoagulation management modalities.

When compared with usual care, coagulation monitoring in dedicated anticoagulation clinics shows a $59 \%$ reduction in major hemorrhagic events and $68 \%$ reduction in thrombotic events when compared with usual care ${ }^{110}$ due to improvements in INR time in a range ${ }^{111}$ leading to reduced bleeding events. ${ }^{112}$ Several studies have shown that PSM of oral anticoagulation using point-of-care coagulometers improves the quality of anticoagulation, thus reducing complication rates and mortality compared with usual care and that it is at least as good as or even slightly better than management in anticoagulation clinics. ${ }^{113-115}$ Accordingly, the current

Table 4 Synopsis of Advantages and Disadvantages of Anticoagulation Management Modalities

\begin{tabular}{|c|c|c|}
\hline Management Modality & Advantages & Disadvantages \\
\hline \multirow[t]{3}{*}{$\begin{array}{l}\text { Usual medical care (venipuncture } \\
\text { and laboratory testing) }\end{array}$} & $\begin{array}{l}\text { Reliable INR results; external quality } \\
\text { control system }\end{array}$ & Time consuming \\
\hline & Results part of an integrated medical record & $\begin{array}{c}\text { Delayed results and } \\
\text { decision making }\end{array}$ \\
\hline & $\begin{array}{l}\text { Dose adjustments and decision making by } \\
\text { a health-care professional }\end{array}$ & $\begin{array}{l}\text { Allows management } \\
\text { of all anticoagulated } \\
\text { patients } \\
\text { Venipuncture necessary } \\
\text { Transportation effects }\end{array}$ \\
\hline \multirow[t]{4}{*}{$\begin{array}{l}\text { PST/PSM (fingerstick and } \\
\text { point-of-care testing) }\end{array}$} & Reliable INR results; internal quality control system & $\begin{array}{l}\text { Lacks external quality } \\
\text { control system }\end{array}$ \\
\hline & Convenient to patients and physicians; easy to use & $\begin{array}{l}\text { Testing needs education } \\
\text { and training }\end{array}$ \\
\hline & Results within minutes allow for rapid decision making & $\begin{array}{l}\text { Some patients may not } \\
\text { be able to carry out } \\
\text { self-testing or } \\
\text { self-management }\end{array}$ \\
\hline & $\begin{array}{l}\text { Use of small specimen volumes; venipuncture } \\
\text { and needlestick injuries can be avoided } \\
\text { Allows patients to take on more responsibility } \\
\text { for their own health }\end{array}$ & \\
\hline $\begin{array}{l}\text { Dedicated management systems } \\
\text { (venipuncture and laboratory } \\
\text { testing or fingerstick and } \\
\text { point-of-care testing) }\end{array}$ & $\begin{array}{l}\text { Reliable INR results; external and/or internal } \\
\text { quality systems }\end{array}$ & $\begin{array}{l}\text { Disadvantages depend on the } \\
\text { testing method used (see above) }\end{array}$ \\
\hline
\end{tabular}

INR, international normalized ratio; PST, patient self-testing; PSM, patient self-management. 
ACCP guidelines advocate PSM and PST for the management of patients with AF. ${ }^{1}$ Better INR control by PSM than by usual care translates into better outcomes of the patients. ${ }^{116}$

Currently, the Department of Veterans Affairs Cooperative Study 481, "The Home INR Study" (THINRS), is underway to compare anticoagulation management with frequent PST using a point-of-care device to high-quality anticoagulation management implemented by an anticoagulation service with conventional monitoring of prothrombin time by INR on major health outcomes. ${ }^{117}$ To assess the effect of PST frequency on oral anticoagulation outcomes, patients randomized to PST are assigned in a substudy of THINRS to weekly, twice-weekly, or once-every4-weeks testing. The results will help to determine the exact place of self-testing versus dedicated care in oral anticoagulation monitoring.

There are regional differences in oral anticoagulation management strategies. In the Netherlands, formal anticoagulation management predominates. Blood is in general drawn by venipuncture, and anticoagulation is managed by anticoagulation clinics. Moreover, pharmacists are integrated in the management of the patients. In Italy, $75 \%$ of the patients are formally managed by their general practitioners but often are self-managed without any formal education. In the United States, health-care environments are extremely diverse, so PSM currently is not applicable. Usually patients are referred to venipuncture, but caring of the patients is informal. In Germany, a sophisticated PSM training system exists. Furthermore, there are important regional differences concerning reimbursement by health insurances: In Germany, where self-management is reimbursed for patients with mechanical heart valves and on a single-case basis also for patients with atrial fibrillation, $<100,000$ patients perform PSM, whereas point-of-care testing by physicians is not adequately reimbursed. In the United Kingdom, test strips needed for point-of-care testing are reimbursed, but not the devices; in Switzerland, a sophisticated PSM training system exists comparable to Germany and $\sim 50$ to $90 \%$ of PSM costs are reimbursed by health insurance companies; in Denmark, $\sim 4 \%$ of patients perform PSM with full reimbursement and 50 to $60 \%$ of INR measurements at general practitioners are performed with point-of-care devices and reimbursed.

\section{Consensus position:}

- Reliable access to accurate INR monitoring is important for optimal management of oral anticoagulation therapy. A formal, structured management style is preferable when available. The frequency of testing has to be determined for each individual patient.

- All methods of INR testing are capable of providing reliable results.
- Dose adjustments of anticoagulants require competency (i.e., trained professionals or educated patients/ surrogates).

\section{REFERENCES}

1. Fuster V, Rydén LE, Cannom DS, et al; American College of Cardiology/American Heart Association Task Force on Practice Guidelines; European Society of Cardiology Committee for Practice Guidelines; European Heart Rhythm Association; Heart Rhythm Society. ACC/ AHA/ESC 2006 Guidelines for the Management of Patients with Atrial Fibrillation: a report of the American College of Cardiology/American Heart Association Task Force on Practice Guidelines and the European Society of Cardiology Committee for Practice Guidelines (Writing Committee to Revise the 2001 Guidelines for the Management of Patients With Atrial Fibrillation): developed in collaboration with the European Heart Rhythm Association and the Heart Rhythm Society. Circulation 2006; 114(7):e257-e354

2. Hylek EM, Go AS, Chang Y, et al. Effect of intensity of oral anticoagulation on stroke severity and mortality in atrial fibrillation. N Engl J Med 2003;349(11):1019-1026

3. Go AS, Hylek EM, Phillips KA, et al. Prevalence of diagnosed atrial fibrillation in adults: national implications for rhythm management and stroke prevention: the AnTicoagulation and Risk Factors in Atrial Fibrillation (ATRIA) Study. JAMA 2001;285(18):2370-2375

4. Kannel WB, Benjamin EJ. Status of the epidemiology of atrial fibrillation. Med Clin North Am 2008; 92(1):1740; ix

5. Feinberg WM, Blackshear JL, Laupacis A, Kronmal R, Hart RG. Prevalence, age distribution, and gender of patients with atrial fibrillation. Analysis and implications. Arch Intern Med 1995;155(5):469-473

6. Miyasaka Y, Barnes ME, Gersh BJ, et al. Secular trends in incidence of atrial fibrillation in Olmsted County, Minnesota, 1980 to 2000, and implications on the projections for future prevalence. Circulation 2006;114(2):119-125

7. WHO Monica Study. Decision resources. Available at: www. $\mathrm{klt} . \mathrm{Fi} / \mathrm{monica}$

8. Statistisches Bundesamt. 2007. Available at: www.destatis.de

9. Davies M, Hobbs F, Davis R, et al. Prevalence of leftventricular systolic dysfunction and heart failure in the Echocardiographic Heart of England Screening study: a population based study. Lancet 2001;358(9280):439444

10. Heeringa J, van der Kuip DA, Hofman A, et al. Prevalence, incidence and lifetime risk of atrial fibrillation: the Rotterdam study. Eur Heart J 2006;27(8):949-953

11. Di Carlo A, Baldereschi M, Gandolfo C, et al; ILSA Working Group; The Italian Longitudinal Study on Aging. Stroke in an elderly population: incidence and impact on survival and daily function. Cerebrovasc Dis 2003;16(2): 141-150

12. Filippi A, Bettoncelli G, Zaninelli A. Detected atrial fibrillation in north Italy: rates, calculated stroke risk and proportion of patients receiving thrombo-prophylaxis. Fam Pract 2000;17(4):337-339

13. National Center of Epidemiology Surveillance and Health Promotion, Italian Institute of Health.. The Italian 
Cardiovascular Epidemiological Observatory. Ital Heart J 2004;5(suppl 3):29S-92S

14. Nieuwlaat R, Capucci A, Camm AJ, et al; European Heart Survey Investigators. Atrial fibrillation management: a prospective survey in ESC member countries: the Euro Heart Survey on Atrial Fibrillation. Eur Heart J 2005;26(22):24222434

15. Friberg J, Scharling H, Gadsbøll N, Truelsen T, Jensen GB; Copenhagen City Heart Study. Comparison of the impact of atrial fibrillation on the risk of stroke and cardiovascular death in women versus men (The Copenhagen City Heart Study). Am J Cardiol 2004;94(7):889-894

16. Wolf PA, Abbott RD, Kannel WB. Atrial fibrillation as an independent risk factor for stroke: the Framingham Study. Stroke 1991;22(8):983-988

17. Page RL, Tilsch TW, Connolly SJ, et al; Azimilide Supraventricular Arrhythmia Program (ASAP) Investigators. Asymptomatic or "silent" atrial fibrillation: frequency in untreated patients and patients receiving azimilide. Circulation 2003;107(8):1141-1145

18. Kerr C, Boone J, Connolly S, et al. Follow-up of atrial fibrillation: the initial experience of the Canadian Registry of Atrial Fibrillation. Eur Heart J 1996;17(suppl C):48-51

19. American Heart Association. Heart disease and stroke statistics. Update. 2008. Available at: www.americanheart. org/presenter.jhtml

20. Dulli DA, Stanko H, Levine RL. Atrial fibrillation is associated with severe acute ischemic stroke. Neuroepidemiology 2003;22(2):118-123

21. Lin HJ, Wolf PA, Kelly-Hayes M, et al. Stroke severity in atrial fibrillation. The Framingham Study. Stroke 1996; 27(10):1760-1764

22. Kannel WB, Abbott RD, Savage DD, McNamara PM. Epidemiologic features of chronic atrial fibrillation: the Framingham study. N Engl J Med 1982;306(17):10181022

23. Vidaillet H, Granada JF, Chyou PH, et al. A populationbased study of mortality among patients with atrial fibrillation or flutter. Am J Med 2002;113(5):365-370

24. Ansell J, Hirsh J, Poller L, Bussey H, Jacobson A, Hylek E. The pharmacology and management of the vitamin $\mathrm{K}$ antagonists: the Seventh ACCP Conference on Antithrombotic and Thrombolytic Therapy. Chest 2004;126(3, suppl): 204S-233S

25. White HD, Gruber M, Feyzi J, et al. Comparison of outcomes among patients randomized to warfarin therapy according to anticoagulant control: results from SPORTIF III and V. Arch Intern Med 2007;167(3):239-245

26. Go AS, Hylek EM, Chang Y, et al. Anticoagulation therapy for stroke prevention in atrial fibrillation: how well do randomized trials translate into clinical practice? JAMA 2003;290(20):2685-2692

27. Hart RG, Benavente O, McBride R, Pearce LA. Antithrombotic therapy to prevent stroke in patients with atrial fibrillation: a meta-analysis. Ann Intern Med 1999;131(7): 492-501

28. Risk factors for stroke and efficacy of antithrombotic therapy in atrial fibrillation. Analysis of pooled data from five randomized controlled trials. Arch Intern Med 1994;154(13):1449-1457

29. Hart RG, Pearce LA, Aguilar MI. Meta-analysis: antithrombotic therapy to prevent stroke in patients who have nonvalvular atrial fibrillation. Ann Intern Med 2007;146(12): 857-867

30. Aguilar MI, Hart R, Pearce LA. Oral anticoagulants versus antiplatelet therapy for preventing stroke in patients with non-valvular atrial fibrillation and no history of stroke or transient ischemic attacks. Cochrane Database Syst Rev 2007;(3):CD006186

31. van Walraven C, Hart RG, Singer DE, et al. Oral anticoagulants vs aspirin in nonvalvular atrial fibrillation: an individual patient meta-analysis. JAMA 2002;288(19):24412448

32. Petersen P, Boysen G, Godtfredsen J, Andersen ED, Andersen B. Placebo-controlled, randomised trial of warfarin and aspirin for prevention of thromboembolic complications in chronic atrial fibrillation. The Copenhagen AFASAK study. Lancet 1989;1(8631):175-179

33. Gulløv AL, Koefoed BG, Petersen P, et al. Fixed minidose warfarin and aspirin alone and in combination vs adjusteddose warfarin for stroke prevention in atrial fibrillation: Second Copenhagen Atrial Fibrillation, Aspirin, and Anticoagulation Study. Arch Intern Med 1998;158(14):15131521

34. Warfarin versus aspirin for prevention of thromboembolism in atrial fibrillation: Stroke Prevention in Atrial Fibrillation II Study. Lancet 1994;343(8899):687-691

35. EAFT (European Atrial Fibrillation Trial) Study Group. Secondary prevention in non-rheumatic atrial fibrillation after transient ischaemic attack or minor stroke. Lancet 1993;342(8882):1255-1262

36. Rash A, Downes T, Portner R, Yeo WW, Morgan N, Channer KS. A randomised controlled trial of warfarin versus aspirin for stroke prevention in octogenarians with atrial fibrillation (WASPO). Age Ageing 2007;36(2):151-156

37. Healey JS, Hart RG, Pogue J, et al. Risks and benefits of oral anticoagulation compared with clopidogrel plus aspirin in patients with atrial fibrillation according to stroke risk: the atrial fibrillation clopidogrel trial with irbesartan for prevention of vascular events (ACTIVE-W). Stroke 2008; 39(5):1482-1486

38. Hu DY, Zhang HP, Sun YH, Jiang LQ; Antithrombotic Therapy in Atrial Fibrillation Study Group. The randomized study of efficiency and safety of antithrombotic therapy in nonvalvular atrial fibrillation: warfarin compared with aspirin [in Chinese]. Zhonghua Xin Xue Guan Bing Za Zhi 2006;34(4):295-298

39. Hellemons BS, Langenberg M, Lodder J, et al. Primary prevention of arterial thromboembolism in non-rheumatic atrial fibrillation in primary care: randomised controlled trial comparing two intensities of coumarin with aspirin. BMJ 1999;319(7215):958-964

40. Pérez-Gómez F, Alegría E, Berjón J, et al; NASPEAF Investigators. Comparative effects of antiplatelet, anticoagulant, or combined therapy in patients with valvular and nonvalvular atrial fibrillation: a randomized multicenter study. J Am Coll Cardiol 2004;44(8):1557-1566

41. Morocutti C, Amabile G, Fattapposta F, et al. Indobufen versus warfarin in the secondary prevention of major vascular events in nonrheumatic atrial fibrillation. SIFA (Studio Italiano Fibrillazione Atriale). Investigators. Stroke 1997;28:1015-1021

42. Mant J, Hobbs FD, Fletcher K, et al; BAFTA investigators; Midland Research Practices Network (MidReC). Warfarin versus aspirin for stroke prevention in an elderly 
community population with atrial fibrillation (the Birmingham Atrial Fibrillation Treatment of the Aged Study, BAFTA): a randomised controlled trial. Lancet 2007; 370(9586):493-503

43. Atwood JE, Albers GW. Anticoagulation and atrial fibrillation. Herz 1993;18(1):27-38

44. Fang MC, Go AS, Chang Y, et al. Death and disability from warfarin-associated intracranial and extracranial hemorrhages. Am J Med 2007;120(8):700-705

45. Levi M, Hovingh GK, Cannegieter SC, Vermeulen M, Büller HR, Rosendaal FR. Bleeding in patients receiving vitamin $\mathrm{K}$ antagonists who would have been excluded from trials on which the indication for anticoagulation was based. Blood 2008;111(9):4471-4476

46. van Walraven C, Hart RG, Singer DE, Koudstaal PJ, Connolly S. Oral anticoagulants vs. aspirin for stroke prevention in patients with non-valvular atrial fibrillation: the verdict is in. Card Electrophysiol Rev 2003;7(4):374378

47. Hylek EM, Evans-Molina C, Shea C, Henault LE, Regan $\mathrm{S}$. Major hemorrhage and tolerability of warfarin in the first year of therapy among elderly patients with atrial fibrillation. Circulation 2007;115(21):2689-2696

48. National Collaborating Centre for Chronic Conditions. Atrial Fibrillation: National Clinical Guideline for Management in Primary and Secondary Care. London, United Kingdom: Royal College of Physicians; 2006

49. Albers GW, Dalen JE, Laupacis A, Manning WJ, Petersen $\mathrm{P}$, Singer DE. Antithrombotic therapy in atrial fibrillation. Chest 2001;119(1, suppl):194S-206S

50. Fumeaux T, Cornuz J, Polikar R, et al. Guidelines for the clinical management of atrial fibrillation: a practical perspective. Swiss Med Wkly 2004;134(17-18):235-247

51. Stroke Risk in Atrial Fibrillation Working Group. Comparison of 12 risk stratification schemes to predict stroke in patients with nonvalvular atrial fibrillation. Stroke 2008; 39(6):1901-1910

52. Hart RG, Halperin JL. Atrial fibrillation and thromboembolism: a decade of progress in stroke prevention. Ann Intern Med 1999;131(9):688-695

53. Gage BF, Waterman AD, Shannon W, Boechler M, Rich MW, Radford MJ. Validation of clinical classification schemes for predicting stroke: results from the National Registry of Atrial Fibrillation. JAMA 2001;285(22):28642870

54. Hylek EM, Singer DE. Risk factors for intracranial hemorrhage in outpatients taking warfarin. Ann Intern Med 1994;120(11):897-902

55. Fihn SD, Callahan CM, Martin DC, McDonell MB, Henikoff JG, White RH; The National Consortium of Anticoagulation Clinics. The risk for and severity of bleeding complications in elderly patients treated with warfarin. Ann Intern Med 1996;124(11):970-979

56. Hart RG, Boop BS, Anderson DC. Oral anticoagulants and intracranial hemorrhage. Facts and hypotheses. Stroke 1995;26(8):1471-1477

57. Hart RG, Aguilar MI. Anticoagulation in atrial fibrillation: selected controversies including optimal anticoagulation intensity, treatment of intracerebral hemorrhage. J Thromb Thrombolysis 2008;25(1):26-32

58. Levine MN, Raskob G, Beyth RJ, Kearon C, Schulman S. Hemorrhagic complications of anticoagulant treatment: the Seventh ACCP Conference on Antithrombotic and
Thrombolytic Therapy. Chest 2004;126(3, suppl):287S$310 \mathrm{~S}$

59. Hylek EM, D’Antonio J, Evans-Molina C, Shea C, Henault LE, Regan S. Translating the results of randomized trials into clinical practice: the challenge of warfarin candidacy among hospitalized elderly patients with atrial fibrillation. Stroke 2006;37(4):1075-1080

60. Fuster V, Rydén LE, Asinger RW, et al; American College of Cardiology; American Heart Association; European Society of Cardiology; North American Society of Pacing and Electrophysiology. ACC/AHA/ESC guidelines for the management of patients with atrial fibrillation. A report of the American College of Cardiology/American Heart Association Task Force on Practice Guidelines and the European Society of Cardiology Committee for Practice Guidelines and Policy Conferences (Committee to develop guidelines for the management of patients with atrial fibrillation) developed in collaboration with the North American Society of Pacing and Electrophysiology. Eur Heart J 2001;22(20):1852-1923

61. Hart RG, Benavente O, Pearce LA. Increased risk of intracranial hemorrhage when aspirin is combined with warfarin: a meta-analysis and hypothesis. Cerebrovasc Dis 1999;9(4):215-217

62. Hart RG, Bhatt DL, Hacke W, et al; CHARISMA Investigators. Clopidogrel and aspirin versus aspirin alone for the prevention of stroke in patients with a history of atrial fibrillation: subgroup analysis of the CHARISMA randomized trial. Cerebrovasc Dis 2008;25(4):344-347

63. Biblo LA, Yuan Z, Quan KJ, Mackall JA, Rimm AA. Risk of stroke in patients with atrial flutter. Am J Cardiol 2001; 87(3):346-349, A9

64. Fang MC, Chang Y, Hylek EM, et al. Advanced age, anticoagulation intensity, and risk for intracranial hemorrhage among patients taking warfarin for atrial fibrillation. Ann Intern Med 2004;141(10):745-752

65. Hylek EM, Skates SJ, Sheehan MA, Singer DE. An analysis of the lowest effective intensity of prophylactic anticoagulation for patients with nonrheumatic atrial fibrillation. N Engl J Med 1996;335(8):540-546

66. Nieuwlaat R, Olsson SB, Lip GY, et al; Euro Heart Survey Investigators; The Euro Heart Survey on Atrial Fibrillation. Guideline-adherent antithrombotic treatment is associated with improved outcomes compared with undertreatment in high-risk patients with atrial fibrillation. Am Heart J 2007; 153(6):1006-1012

67. Ang SY, Peterson GM, Friesen WT, Vial JH. Review of antithrombotic drug usage in atrial fibrillation. J Clin Pharm Ther 1998;23(2):97-106

68. Paciaroni M, Agnelli G, Caso V, et al. Atrial fibrillation in patients with first-ever stroke: frequency, antithrombotic treatment before the event and effect on clinical outcome. J Thromb Haemost 2005;3(6):1218-1223

69. Ferro D, Loffredo L, Polimeni L, Violi F. Underuse of oral anticoagulants in patients with nonvalvular atrial fibrillation in Italy. Intern Emerg Med 2007;2(1):24-28

70. Zehnder BS, Schaer BA, Jeker U, Cron TA, Osswald S. Atrial fibrillation: estimated excess rate of stroke due to lacking adherence to guidelines. Swiss Med Wkly 2006; 136(47-48):757-760

71. Beyth RJ, Antani MR, Covinsky KE, et al. Why isn't warfarin prescribed to patients with nonrheumatic atrial fibrillation? J Gen Intern Med 1996;11(12):721-728 
72. Chang HJ, Bell JR, Deroo DB, Kirk JW, Wasson JH. Physician variation in anticoagulating patients with atrial fibrillation. Dartmouth Primary Care COOP Project. Arch Intern Med 1990;150(1):83-86

73. Partington SL, Abid S, Teo K, Oczkowski W, O’Donnell MJ. Pre-admission warfarin use in patients with acute ischemic stroke and atrial fibrillation: the appropriate use and barriers to oral anticoagulant therapy. Thromb Res 2007;120(5):663-669

74. Choudhry NK, Anderson GM, Laupacis A, Ross-Degnan D, Normand SL, Soumerai SB. Impact of adverse events on prescribing warfarin in patients with atrial fibrillation: matched pair analysis. BMJ 2006;332(7534):141-145

75. Gattellari M, Worthington J, Zwar N, Middleton S. Barriers to the use of anticoagulation for nonvalvular atrial fibrillation: a representative survey of Australian family physicians. Stroke 2008;39(1):227-230

76. Dinh $T$, Nieuwlaat R, Tieleman RG, et al. Antithrombotic drug prescription in atrial fibrillation and its rationale among general practitioners, internists and cardiologists in The Netherlands-The EXAMINE-AF study. A questionnaire survey. Int J Clin Pract 2007;61(1):24-31

77. Deplanque D, Leys D, Parnetti L, et al; SAFE II Investigators. Stroke prevention and atrial fibrillation: reasons leading to an inappropriate management. Main results of the SAFE II study. Br J Clin Pharmacol 2004; 57(6):798-806

78. Hasenkamp JM, Sygehus S. Living with anticoagulants. Paper presented at: World Congress of Cardiology; 2006; Barcelona, Spain

79. Lip GY, Golding DJ, Nazir M, Beevers DG, Child DL, Fletcher RI. A survey of atrial fibrillation in general practice: the West Birmingham Atrial Fibrillation Project. Br J Gen Pract 1997;47(418):285-289

80. Kimmel SE, Chen Z, Price M, et al. The influence of patient adherence on anticoagulation control with warfarin: results from the International Normalized Ratio Adherence and Genetics (IN-RANGE) Study. Arch Intern Med 2007; 167(3):229-235

81. Nieuwlaat R, Capucci A, Lip GY, et al; Euro Heart Survey Investigators. Antithrombotic treatment in real-life atrial fibrillation patients: a report from the Euro Heart Survey on Atrial Fibrillation. Eur Heart J 2006;27(24):30183026

82. Arnsten JH, Gelfand JM, Singer DE. Determinants of compliance with anticoagulation: a case-control study. Am J Med 1997;103(1):11-17

83. Lane DA, Ponsford J, Shelley A, Sirpal A, Lip GY. Patient knowledge and perceptions of atrial fibrillation and anticoagulant therapy: effects of an educational intervention programme. The West Birmingham Atrial Fibrillation Project. Int J Cardiol 2006;110(3):354-358

84. Wofford JL, Wells MD, Singh S. Best strategies for patient education about anticoagulation with warfarin: a systematic review. BMC Health Serv Res 2008;8:40

85. Sawicki PT; Working Group for the Study of Patient SelfManagement of Oral Anticoagulation. A structured teaching and self-management program for patients receiving oral anticoagulation: a randomized controlled trial. JAMA 1999;281(2):145-150

86. Wilson FL, Racine E, Tekieli V, Williams B. Literacy, readability and cultural barriers: critical factors to consider when educating older African Americans about anticoagulation therapy. J Clin Nurs 2003;12(2):275-282

87. Reynolds MW, Fahrbach K, Hauch O, et al. Warfarin anticoagulation and outcomes in patients with atrial fibrillation: a systematic review and metaanalysis. Chest 2004; 126(6):1938-1945

88. Stroke Prevention in Atrial Fibrillation Study. Final results. Circulation 1991;84(2):527-539

89. The Boston Area Anticoagulation Trial for Atrial Fibrillation Investigators. The effect of low-dose warfarin on the risk of stroke in patients with nonrheumatic atrial fibrillation. N Engl J Med 1990;323(22):1505-1511

90. Connolly SJ, Laupacis A, Gent M, Roberts RS, Cairns JA, Joyner C. Canadian Atrial Fibrillation Anticoagulation (CAFA) Study. J Am Coll Cardiol 1991;18(2):349-355

91. Ezekowitz MD, Bridgers SL, James KE, et al; Veterans Affairs Stroke Prevention in Nonrheumatic Atrial Fibrillation Investigators. Warfarin in the prevention of stroke associated with nonrheumatic atrial fibrillation. N Engl J Med 1992;327(20):1406-1412

92. Hirsh J, Dalen JE, Deykin D, Poller L. Oral anticoagulants. Mechanism of action, clinical effectiveness, and optimal therapeutic range. Chest 1992;102(4, suppl):312S-326S

93. Bajpai A, Savelieva I, Camm AJ. Epidemiology and economic burden of atrial fibrillation. US Cardiovasc Dis 2007;1:14-17

94. Wattigney WA, Mensah GA, Croft JB. Increasing trends in hospitalization for atrial fibrillation in the United States, 1985 through 1999: implications for primary prevention. Circulation 2003;108(6):711-716

95. Stewart S, Murphy NF, Murphy N, Walker A, McGuire A, McMurray JJ. Cost of an emerging epidemic: an economic analysis of atrial fibrillation in the UK. Heart 2004;90(3): 286-292

96. Le Heuzey JY, Paziaud O, Piot O, et al. Cost of care distribution in atrial fibrillation patients: the COCAF study. Am Heart J 2004;147(1):121-126

97. Coyne KS, Paramore C, Grandy S, Mercader M, Reynolds M, Zimetbaum P. Assessing the direct costs of treating nonvalvular atrial fibrillation in the United States. Value Health 2006;9(5):348-356

98. Szucs TD, Bramkamp M. Pharmacoeconomics of anticoagulation therapy for stroke prevention in atrial fibrillation: a review. J Thromb Haemost 2006;4(6):1180-1185

99. Jones M, McEwan P, Morgan CL, Peters JR, Goodfellow J, Currie CJ. Evaluation of the pattern of treatment, level of anticoagulation control, and outcome of treatment with warfarin in patients with non-valvar atrial fibrillation: a record linkage study in a large British population. Heart 2005;91(4):472-477

100. Regier DA, Sunderji R, Lynd LD, Gin K, Marra CA. Costeffectiveness of self-managed versus physician-managed oral anticoagulation therapy. CMAJ 2006;174(13):1847-1852

101. Caro JJ. An economic model of stroke in atrial fibrillation: the cost of suboptimal oral anticoagulation. Am J Manag Care 2004;10(14, suppl):S451-S458; discussion S458-S461

102. van Geest-Daalderop JH, Hutten BA, Péquériaux NC, Haas FJ, Levi M, Sturk A. The influence on INRs and coagulation factors of the time span between blood sample collection and intake of phenprocoumon or acenocoumarol: consequences for the assessment of the dose. Thromb Haemost 2007;98(4):738-746 
103. Phillips KW, Ansell J. Outpatient management of oral vitamin $\mathrm{K}$ antagonist therapy: defining and measuring highquality management. Expert Rev Cardiovasc Ther 2008; 6(1):57-70

104. Bernardo A, Völler H. Arbeitsgemeinschaft Selbstkontrolle der Antikoagulation (ASA) [Guidelines for "coagulation self-management”]. Dtsch Med Wochenschr 2001;126(12): 346-351

105. Ansell J, Jacobson A, Levy J, Völler H, Hasenkam JM; International Self-Monitoring Association for Oral Anticoagulation. Guidelines for implementation of patient selftesting and patient self-management of oral anticoagulation. International consensus guidelines prepared by International Self-Monitoring Association for Oral Anticoagulation. Int J Cardiol 2005;99(1):37-45

106. Fihn SD, McDonell MB, Vermes D, et al; National Consortium of Anticoagulation Clinics. A computerized intervention to improve timing of outpatient follow-up: a multicenter randomized trial in patients treated with warfarin. J Gen Intern Med 1994;9(3):131-139

107. Fitzmaurice DA, Hobbs FD, Delaney BC, Wilson S, McManus R. Review of computerized decision support systems for oral anticoagulation management. Br J Haematol 1998;102(4):907-909

108. Fitzmaurice DA, Hobbs FD, Murray ET, Holder RL, Allan $\mathrm{TF}$, Rose PE. Oral anticoagulation management in primary care with the use of computerized decision support and near-patient testing: a randomized, controlled trial. Arch Intern Med 2000;160(15):2343-2348

109. Manotti C, Moia M, Palareti G, Pengo V, Ria L, Dettori AG. Effect of computer-aided management on the quality of treatment in anticoagulated patients: a prospective, randomized, multicenter trial of APROAT (Automated PRogram for Oral Anticoagulant Treatment). Haematologica 2001;86(10):1060-1070
110. Ansell JE. Optimizing the efficacy and safety of oral anticoagulant therapy: high-quality dose management, anticoagulation clinics, and patient self-management. Semin Vasc Med 2003;3(3):261-270

111. Ansell J, Hollowell J, Pengo V, Martinez-Brotons F, Caro J, Drouet L. Descriptive analysis of the process and quality of oral anticoagulation management in real-life practice in patients with chronic non-valvular atrial fibrillation: the international study of anticoagulation management (ISAM). J Thromb Thrombolysis 2007; 23(2):83-91

112. Nichol MB, Knight TK, Dow $\mathrm{T}$, et al. Quality of anticoagulation monitoring in nonvalvular atrial fibrillation patients: comparison of anticoagulation clinic versus usual care. Ann Pharmacother 2008;42(1):62-70

113. Cromheecke ME, Levi M, Colly LP, et al. Oral anticoagulation self-management and management by a specialist anticoagulation clinic: a randomised cross-over comparison. Lancet 2000;356(9224):97-102

114. Völler H, Glatz J, Taborski U, Bernardo A, Dovifat C, Heidinger K. Self-management of oral anticoagulation in nonvalvular atrial fibrillation (SMAAF study). Z Kardiol 2005;94(3):182-186

115. Heneghan C, Alonso-Coello P, Garcia-Alamino JM, Perera R, Meats E, Glasziou P. Self-monitoring of oral anticoagulation: a systematic review and meta-analysis. Lancet 2006;367(9508):404-411

116. Menéndez-Jándula B, Souto JC, Oliver A, et al. Comparing self-management of oral anticoagulant therapy with clinic management: a randomized trial. Ann Intern Med 2005; 142(1):1-10

117. Matchar DB, Jacobson AK, Edson RG, et al. The impact of patient self-testing of prothrombin time for managing anticoagulation: rationale and design of VA Cooperative Study \#481- the Home INR Study (THINRS). J Thromb Thrombolysis 2005;19(3):163-172 